\title{
Compact UWB Filtering-Antenna with Controllable WLAN Band Rejection Using Defected Microstrip Structure
}

\author{
Ammar ALHEGAZI, Zahriladha ZAKARIA, Noor Azwan SHAIRI, Azahari SALLEH, Sharif AHMED \\ Centre of Telecommunication Research and Innovation (CeTRI), Fakulti Kejuruteraan Elektronik dan Kejuruteraan \\ Komputer (FKEKK), Universiti Teknikal Malaysia Melaka (UTeM), Hang Tuah Jaya 76100, Melaka, Malaysia \\ ammarhejazy@hotmail.com, zahriladha@utem.edu.my
}

Submitted May 13, 2017 / Accepted November 1, 2017

\begin{abstract}
An ultra-wideband (UWB) filtering-antenna with controllable band notch is reported in this paper. The filtering-antenna consists of a modified monopole antenna and defected microstrip structure (DMS). The monopole antenna is modified using microstrip transition in the feedline and block with a triangular-shape slot on each side of the circular patch to produce wider impedance bandwidth with better return loss. The DMS is constructed using $U$-shaped slot etched on the feedline to provide band notch and remove WLAN band (5.1-5.8 GHz). A switch is employed in the DMS to control the created band notch. The measured results show that the proposed design exhibits a wide impedance bandwidth with controllable WLAN band rejection, realized peak gain of $4.85 \mathrm{~dB}$ and omnidirectional radiation pattern. Therefore, the proposed design is suitable for UWB applications.
\end{abstract}

\section{Keywords}

Bandstop filter, defected microstrip structure, filtenna, monopole antenna, reconfigurable antenna, ultrawideband (UWB)

\section{Introduction}

Ultra-wideband (UWB) technology attracts recent developments in wireless communication systems due to its unique advantages such as low power consumption, wide impedance bandwidth and high data rate for short range. The main feature of the UWB technology is the ability to carry signals through doors and others obstacles that tend to reflect signals with high power and limited bandwidth, thus it has been incorporated into many applications in other fields such as wireless communications, radar applications and medical engineering [1]-[3]. Printed monopole antennas are suitable for UWB technology because of their advantages such as light weight, low profile, low cost, small size and omnidirectional radiation pattern [4], [5]. However, the narrow band technologies (e.g., WLAN and
HiperLAN) cause interference with the UWB technology, which reduces the performance of the UWB system [6]. Therefore, the UWB system is integrated with a bandstop filter to eliminate unwanted frequencies and avoid the interference problem. The conventional UWB system is integrated with the bandstop filter in a separated model from the antenna, which leads to increase losses, size, complexity and cost [7], thus it is desirable to integrate the microwave filter and antenna into a single design to provide radiating and filtering functions simultaneously. Recently, reconfigurable antennas have gained tremendous research interest in modern technologies such as cellular radio system, radar system, aircraft, mobile, satellite communications, Unmanned Airborne Vehicle (UAV) radar, smart weapon protection and microwave imaging that requires flexibility to support many standards (e.g., UMTS, Bluetooth, WiFi, WiMAX, DSRC), mitigate strong interference signals and cope with the changing environmental condition [8], [9].

The antenna with filtering function is known as filtering-antenna or filtenna. Filtering-antenna has several advantages such as miniaturize the size, simplify the design, reduce the losses and multifunction operation [10]. Thus, there is a growing interest to integrate resonant structures in the antenna design to produce stopband characteristics using different techniques. Most researchers used microstrip structures to construct the filtering-antenna such as introducing different forms of slots or structures on the radiating patch of the antenna [11]-[14]. In [13], an ultra-wideband monopole antenna with a single band notch was proposed. In this topology, the band notch was produced by inserting a key and U-shaped slots on the radiating patch. However, it showed a bidirectional radiation pattern in the azimuth plane. In [14], the band notch was achieved by etching slits and half wavelength stubs on the radiating patch. However, the results showed lower cross-polarization due to the notch structure on the radiation patch. Another technique by using defected ground structure (DGS) is reported in [15]. In this design, the band notch was created by removing two squares in the ground plane. However, the disadvantage of the DGS technique is 
the wave leakage through the ground plane, which influences the radiation characteristics such as a variation of the radiation patterns at higher frequencies [16], [17]. The coupling technique was proposed in [18]. In this design, the band rejection was produced by coupling an open stub with a parasitic of inverted L-shaped inserted in a monopole antenna to reject the WLAN band. However, coupling techniques have a complex structure and hard to miniaturize. Some researchers used horn antennas to construct filtering-antenna [19]-[21]. The main advantage of the horn antenna is its efficiency to provide directed waves, which is suitable for aircraft applications. However, the disadvantage of horn antennas is the large size, which is not suitable for printed circuit board (PCB) technology. The created band notch can be controlled by incorporating active component into the resonant structure. In [22], [23] a switch was employed in the defected patch structure to switch ON and OFF the created band notch. In [24] a switch was employed in the defected ground structure to control (ON/OFF) the band notch. However, incorporating active components in the radiating patch or ground plane influences the performance of the antenna because of the biasing network. A varactor diode is employed in the band notch structure to tune the created band notch as studied in [25], [26]. However, tuning the created band notch may cut a portion of the received information once the interfering signal does not exist, which degrade the performance of the receiver in the UWB system.

From the literature, it can be noted that most researchers tend to use microstrip structure techniques due to their attractive advantages such as easy to fabricate, low in manufacturing cost and easy to integrate with any planar structure. However, previous topologies produced the band notch using resonant structures on the radiating patch or ground plane which may influence the performance of the antenna. In this paper, a modified printed monopole antenna is designed to achieve wide impedance bandwidth. U-shaped slot is etched on the feedline to provide band notch characteristics with high selectivity. The band rejection structure is integrated in the feedline to miniaturize the design, avoid the leakage through the ground plane, and provide stable omnidirectional azimuth pattern. The created band notch is tuned by adjusting the dimensions of the $\mathrm{U}$-shaped slot. The created band notch is electronically controlled using BAP64-02 PIN diode. The gain and radiation pattern of the proposed design are measured and presented.

\section{Antenna Design}

The antenna is simulated using Computer Simulation Technology (CST). The substrate material used for this design is Rogers RT/Duroid 5880, which has a relative permittivity of $\varepsilon_{\mathrm{r}}=2.2$, loss tangent of $\tan \delta=0.0009$ and thickness of $d=0.787 \mathrm{~mm}$. The simulated structure of the proposed filtering-antenna is shown in Fig. 1. Regarding the modification of the UWB monopole antenna by pro-

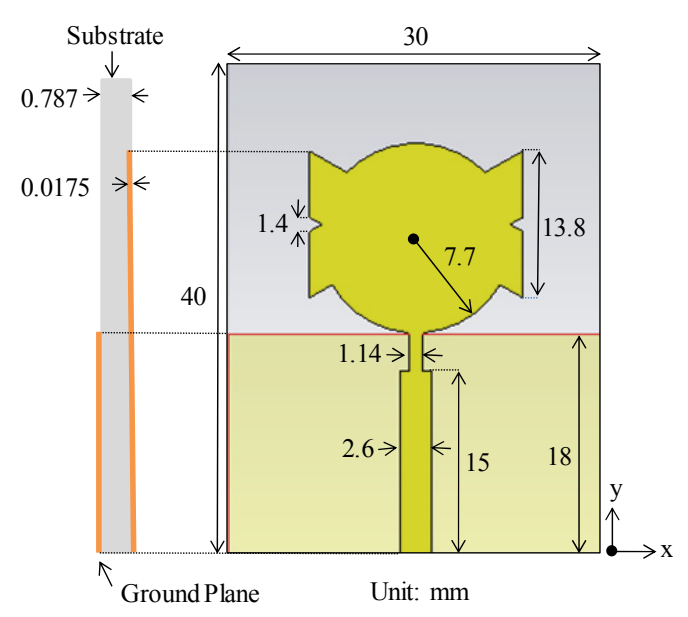

Fig. 1. Simulated structure of the UWB antenna.

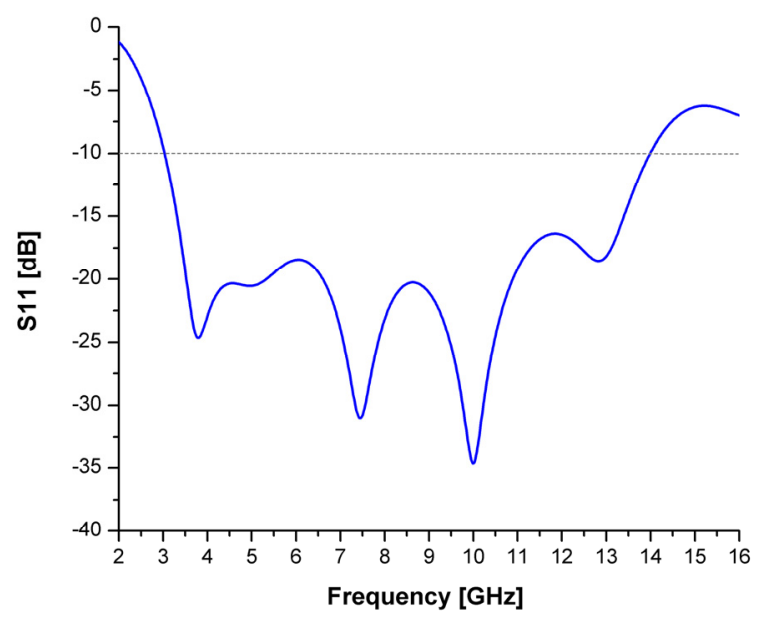

Fig. 2. Simulated return loss of the UWB antenna.

ducing a simple microstrip transitions between the feedline and the patch, the return loss of the antenna is improved as explained in details in [27]. Furthermore, the return loss at higher frequencies is improved by placing a block with triangular shape slot on each side of the circular patch. Figure 2 shows the simulated return loss of the UWB monopole antenna. The simulated result shows that the modified UWB antenna exhibits a wide impedance bandwidth with high frequency skirt selectivity covering the frequency band from 3 to $14 \mathrm{GHz}$.

\section{Filtering-Antenna Configuration}

A resonant structure is integrated into the antenna design to form the proposed filtering-antenna. The resonant structure is constructed using U-shaped slot etched on the feedline as shown in Fig. 3(a). The antenna provides wide impedance bandwidth and the U-shaped slot produces the band rejection to eliminate WLAN frequency band. The U-shaped slot is designed at resonant frequency of $5.45 \mathrm{GHz}$ with length of a quarter of the wavelength [28]. The U-shaped slot influences the behavior of the current flow in the feedline and leads to produce band notch characteristics. 


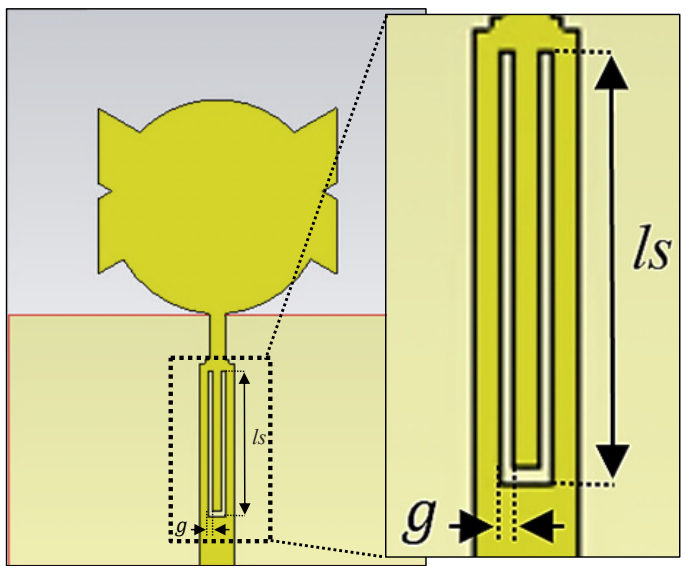

(a)

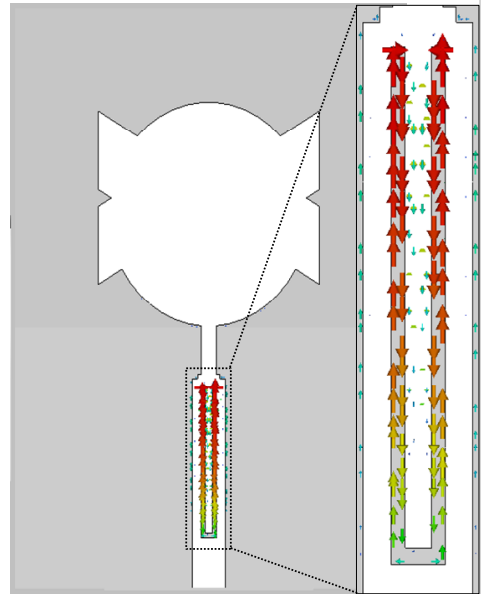

(b)

Fig. 3. Proposed filtering-antenna: (a) Simulated structure. (b) Simulated surface current distribution at $5.45 \mathrm{GHz}$.

Figure 3(b) shows the surface current distribution at the notch frequency, it can be seen that the current is more focused on the DMS and flows around the edges in opposite directions with the same magnitude, which leads to cancel each other and to produce high attenuation at that frequency. Thus, the antenna does not radiate, and therefore band notch is created [29].

The band notch can be tuned by changing the width and length of the DMS. Figure 4 shows different position of the band notch with length variation of the DMS, it can be seen that the band notch can be tuned along wide frequency range and as the length of the DMS increases the resonant frequency of the band notch decreases, thus the result shows a band notch at $5.45 \mathrm{GHz}$ when the length is $10.5 \mathrm{~mm}$, while it shows a band notch at $7.5 \mathrm{GHz}$ when the length is $7.5 \mathrm{~mm}$. The bandwidth of the created band notch can be tuned from 0.475 to more than $1.5 \mathrm{GHz}$ by changing the width of the DMS as shown in Fig. 5.

The frequency reconfiguration feature is achieved by employing an ideal switch (SW) in the DMS as shown in Fig. 6. The function of the ideal switch can be demonstrated by using copper strip, where the DMS acts as a short circuit (SC) in the ON state, while in the OFF state the DMS acts as an open circuit (OC). In other words, the

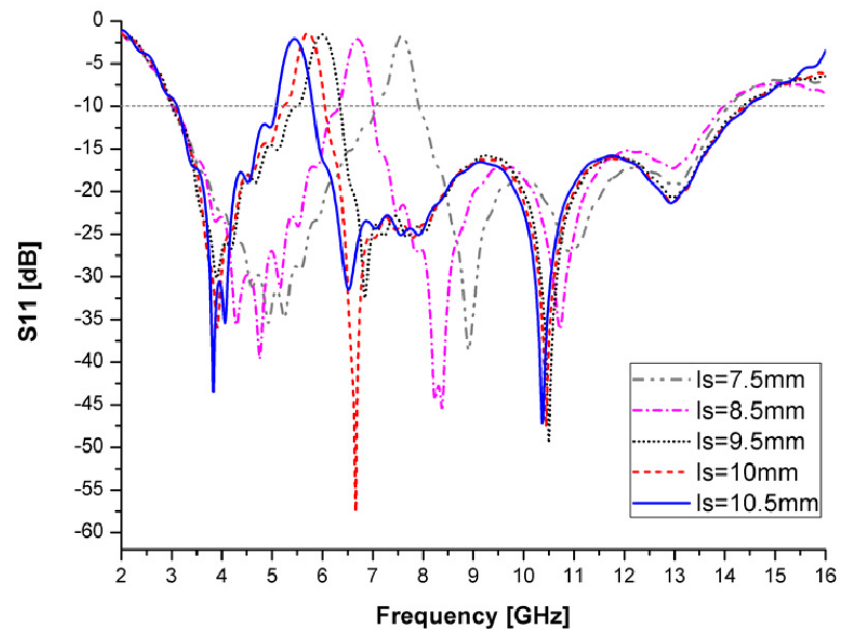

Fig. 4. Simulated return loss of the proposed filtering antenna with length variation of the DMS.

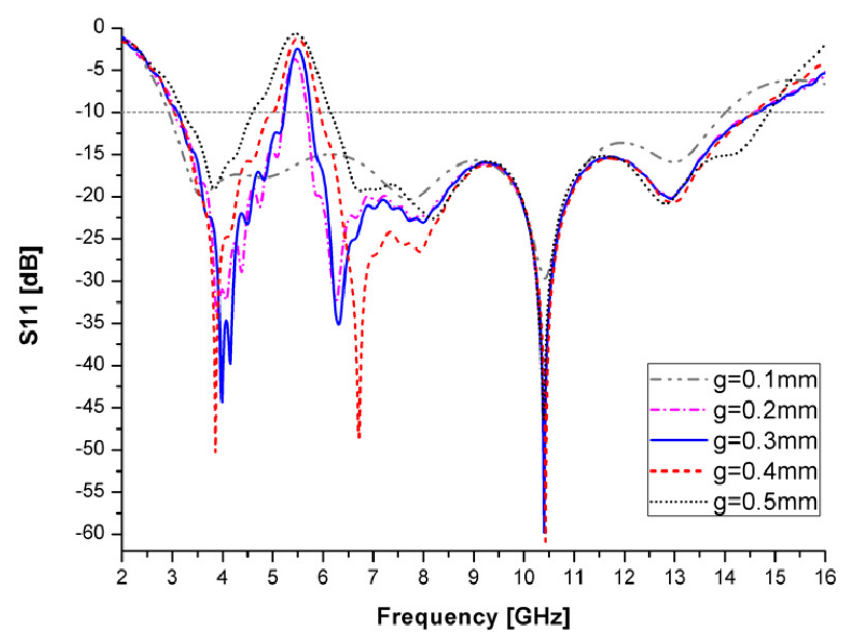

Fig. 5. Simulated return loss of the proposed filtering-antenna with width variation of the DMS.

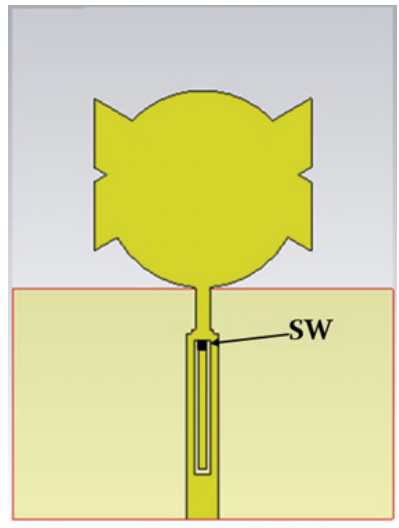

Fig. 6. Proposed filtering-antenna with ideal switch.

existence of the copper strip shows that the switch condition is ON state; in contrast, the absence of the copper strip shows that the switch condition is OFF state. From Fig. 7 in the ON state (SC) the DMS acts as U-shaped slot which influences the distribution of the current flow at the band notch frequency and leads to produce band notch characteristics, while in the OFF state (OC) the DMS acts as 


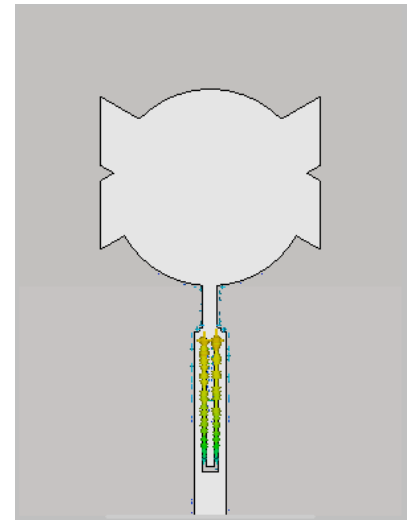

(a)

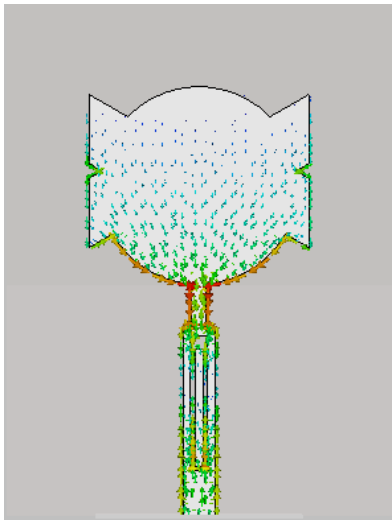

(b)
Fig. 7. Simulated surface current distribution at $5.45 \mathrm{GHz}$ for (a) SC, (b) OC.

a rectangular ring slot which allows the current to flow in the feedline and patch normally, and then allows the signal to pass at the band notch frequency.

To control the created band notch electronically, a PIN diode switch is used instated of the ideal switch as shown in Fig. 8. The PIN diode acts as a variable resistor with two operating status (ON/OFF) [30]. Both states of the PIN diode have equivalent RLC circuit. The equivalent circuit for the ON state (forward biased) has a low resistance which allows the current to pass and acts as short circuit, while in the OFF state (zero or revers biased), it has a parallel combination of capacitance and large resistance which blocks the flow of current and acts as open circuit. The values of the RLC elements in both states are given in a standard PIN diode data sheet. Silicon PIN diode BAP6402 is used to achieve frequency reconfiguration. The BAP64-02 PIN diode is modeled in CST using RLC lumped network element condition. The equivalent RLC circuits with required values of the BAP64-02 are shown in Fig. 9 [30].

\section{Results and Discussions}

The proposed filtering-antenna with ideal switch is fabricated and shown in Fig. 10. The simulated and measured return loss of the proposed filtering-antenna using ideal switch is shown in Fig. 11. The simulated results show that the proposed filtering-antenna in the OC case provides a bandwidth from 3.1 to $14.4 \mathrm{GHz}$, while in the $\mathrm{SC}$ case it provides a bandwidth from 3.1 to $14.4 \mathrm{GHz}$ with band notch from 5.1 to $5.8 \mathrm{GHz}$. On the other hand, the measured results show that the proposed filtering-antenna in the $\mathrm{OC}$ case has a bandwidth from 2.7 to $15.15 \mathrm{GHz}$, while in the SC case it has a frequency bandwidth from 3.55 to $16 \mathrm{GHz}$ with band notch from 4.83 to $5.96 \mathrm{GHz}$. However, there is a small variation between the simulated and measured results due to the tangent loss of the substrate and the fabrication tolerance.

The proposed filtering-antenna with PIN diode switch is fabricated and shown in Fig. 12. The simulated and measured return loss of the proposed filtering-antenna using

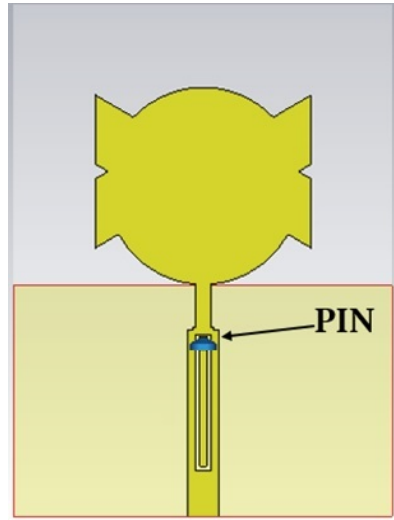

Fig. 8. Proposed filtering-antenna with PIN diode switch.

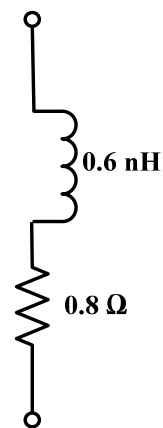

(a)

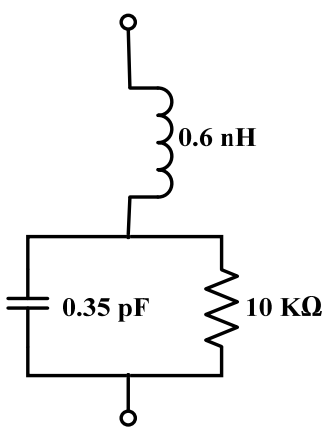

(b)
Fig. 9. RLC equivalent circuit of the BAP64-02 PIN diode at: (a) ON state, (b) OFF state.

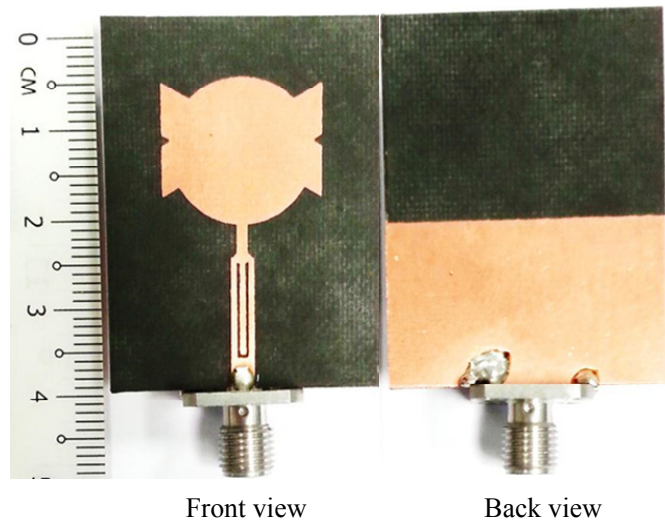

(a)

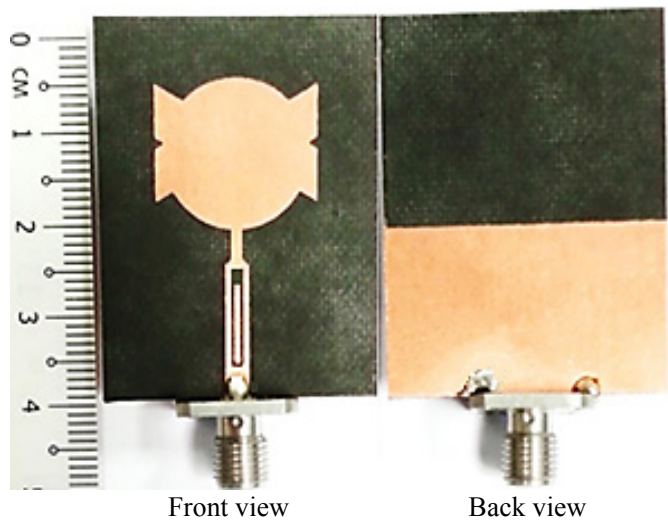

(b)

Fig. 10. Fabricated structure of the proposed filtering-an tenna with ideal switch in (a) SC case, (b) OC case. 


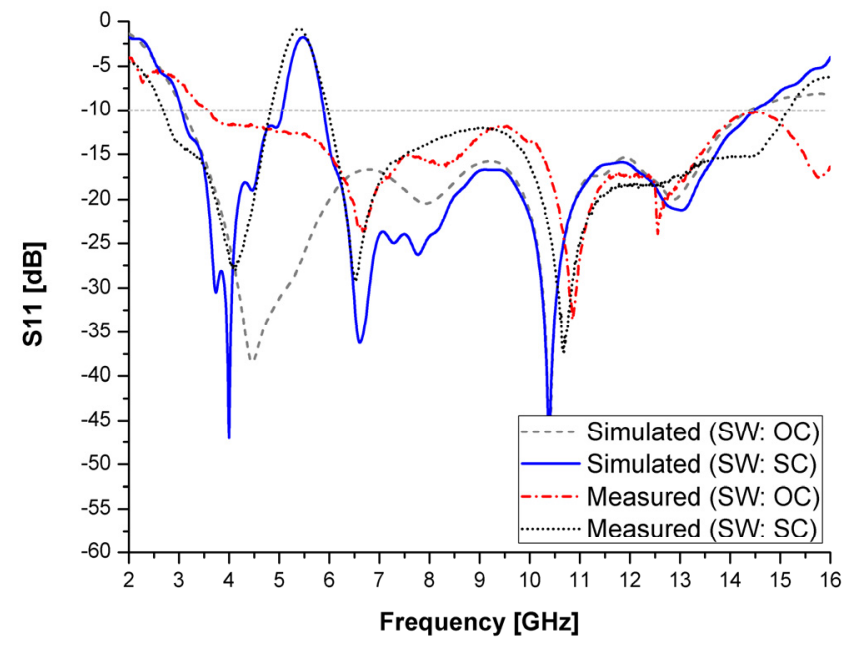

Fig. 11. Simulated and measured return loss of the proposed filtering-antenna using ideal switch.

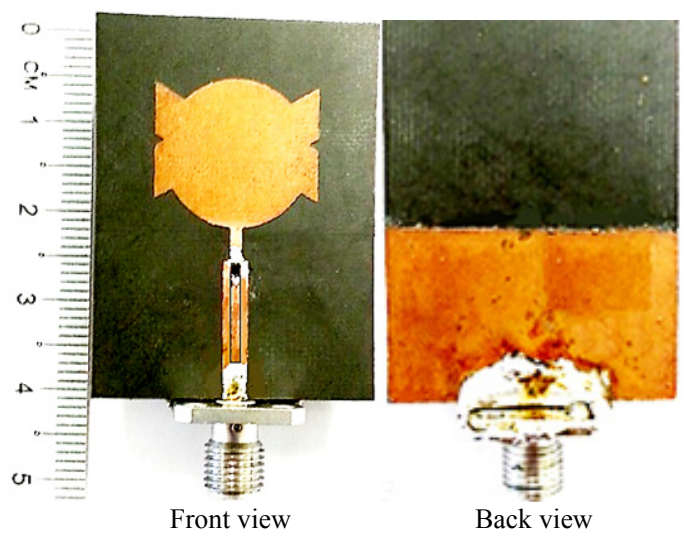

Fig. 12. Fabricated structure of the proposed filteringantenna with PIN diode switch.

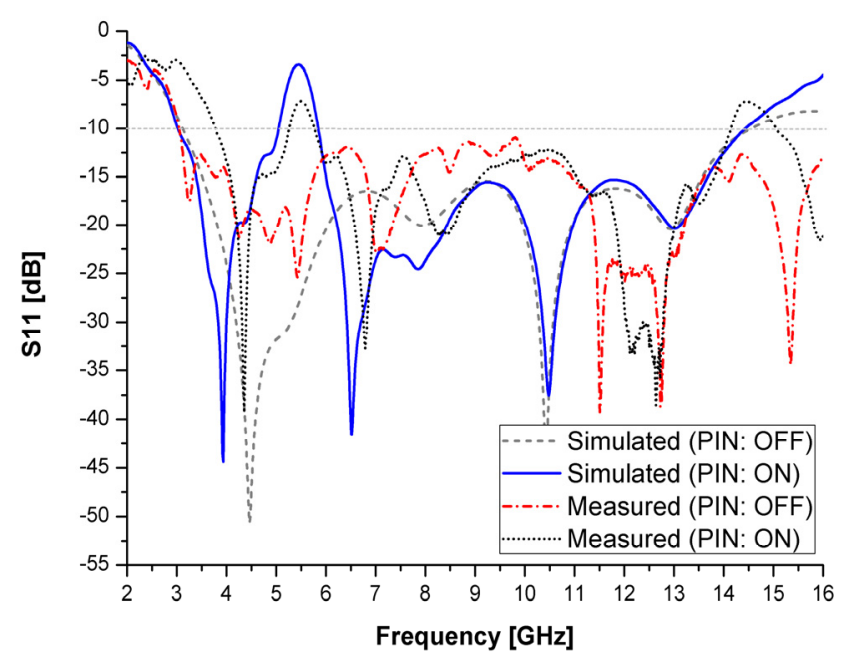

Fig. 13. Simulated and measured return loss of the proposed filtering-antenna using PIN diode switch.

PIN diode switch is shown in Fig. 13. The simulated results show that the proposed filtering-antenna in the ON state provides a bandwidth from 3 to $14.4 \mathrm{GHz}$ with band notch from 5.1 to $5.8 \mathrm{GHz}$, while in the OFF state it has the same bandwidth without band notch. The measured results show that the proposed filtering-antenna in the ON state provides a bandwidth from 3.77 to $14.13 \mathrm{GHz}$ with band notch from 5.25 to $5.76 \mathrm{GHz}$, while in the OFF state it provides a frequency bandwidth from 3.05 to $16 \mathrm{GHz}$ without band notch. However, small frequency shift of $50 \mathrm{MHz}$ is noted, where the measured center frequency of the band notch appears at $5.5 \mathrm{GHz}$ and the simulated one appears at $5.45 \mathrm{GHz}$, which means that the frequency shift is about $0.89 \%$, this is mainly due to the variation of the substrate permittivity which is $2.2 \pm 0.02(\approx 0.91 \%)$. In addition, the return loss of the measured band notch is decreased compared to the simulated one due to the current limit of the PIN diode at the ON state, where the maximum supplied voltage is $1.1 \mathrm{~V}$ [31]. Moreover, the performance of the PIN diode switch BAP64-02 decreases at higher frequencies (more than $2 \mathrm{GHz}$ ) as studied in [32]. Therefore, to investigate and demonstrate a controllable band notch using active components, PIN diode BAP64-02 is chosen.

Figure 14 shows the measured gain of the fabricated filtering-antenna in the SC case. The result shows that the gain of the proposed filtering-antenna is more than $1 \mathrm{~dB}$ with a peak value of $4.85 \mathrm{~dB}$ over the operating band from 3 to $10 \mathrm{GHz}$ except at the band notch frequencies where the gain significantly reduces. However, the gain is decreasing gradually over the operating band from 10 to $13.5 \mathrm{GHz}$ due to the antenna misalignment and surrounding environment which cause power loss [33]. In addition, the dissipation factor of the substrate and the presence of higher order operational modes contribute to reducing the gain at higher frequencies as studied in [34-36].

Figure 15 illustrates the simulated and measured radiation patterns of the proposed filtering-antenna in the SC case at several frequencies, including H-plane and E-plane. It can be observed that the proposed filtering antenna provides omnidirectional radiation pattern. However, ripples are noted in the measured radiation patterns, due to the small size of the patch [33]. Furthermore, the radiation patterns degrade at higher frequencies due to the presence of the higher order operational modes.

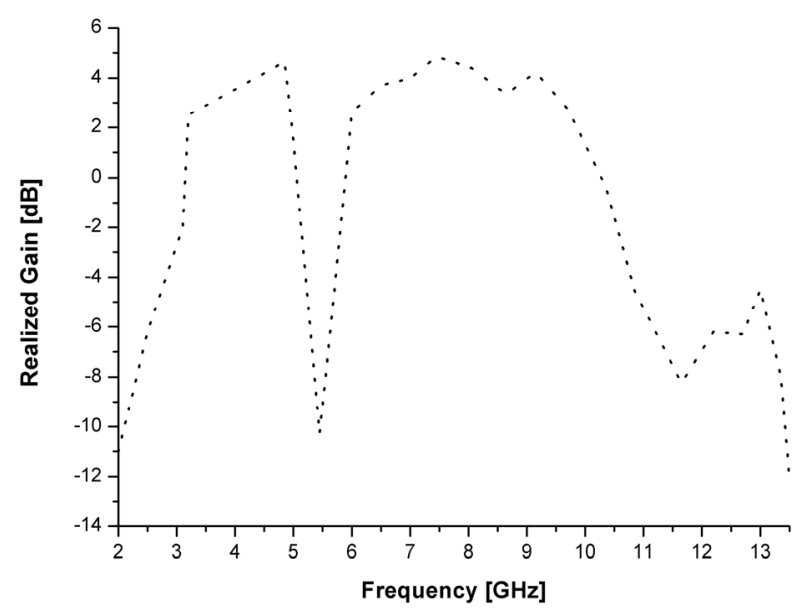

Fig. 14. Measured gain of the proposed filtering-antenna in the SC case. 


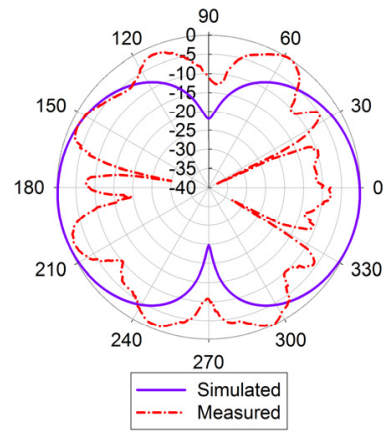

(a)
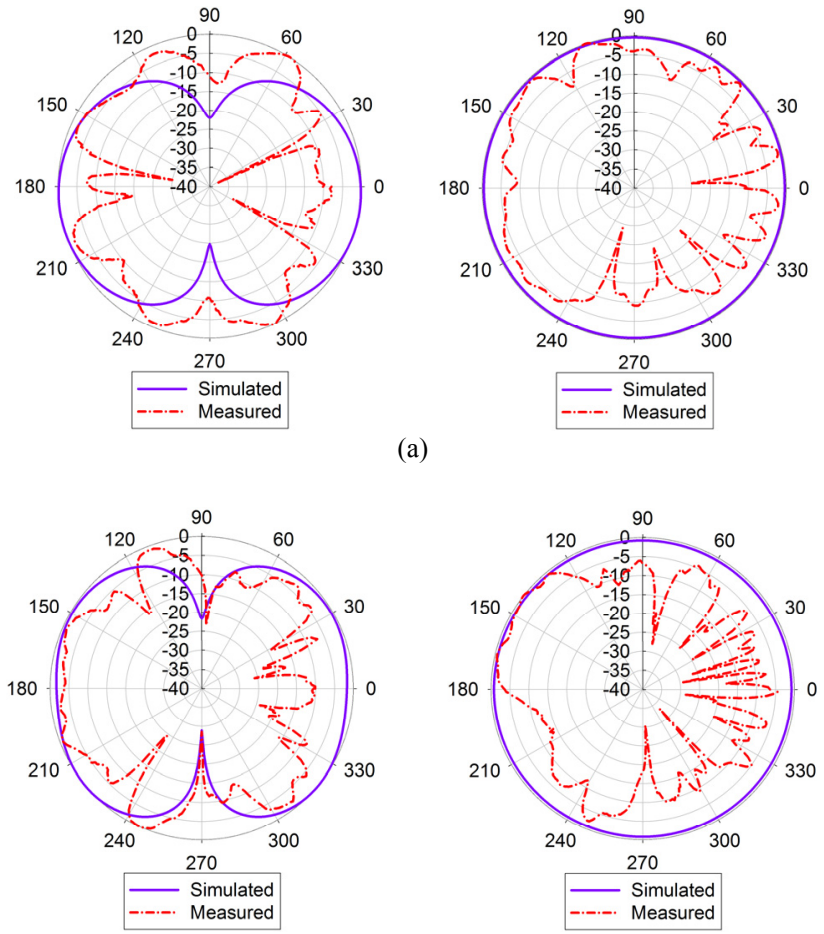

(b)
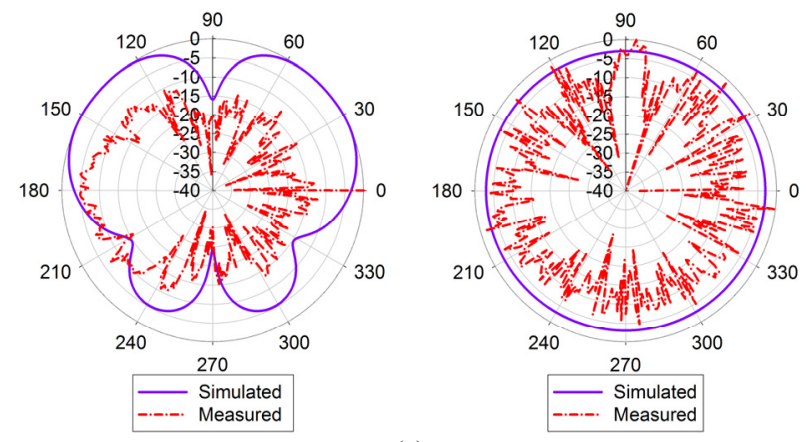

(c)

Fig. 15. Simulated and measured radiation pattern of the proposed filtering-antenna at: (a) $4 \mathrm{GHz}$, (b) $6.5 \mathrm{GH}$, (c) $9.5 \mathrm{GHz}$.

\section{Conclusion}

A modified UWB monopole antenna integrated with defected microstrip structure (DMS) for UWB applications has been reported. The proposed design without DMS shows a wideband performance of bandwidth covering the entire UWB frequency band $(3.1-10.6 \mathrm{GHz})$. The band notch is created by defecting a U-shaped slot in the feedline. The band notch can be tuned by changing the width and length of the DMS. A PIN diode is employed in the DMS to control the created band notch electronically. The results show that the proposed filtering-antenna provides a wide bandwidth with controllable band notch to filter out WLAN frequencies, the realized peak gain of $4.85 \mathrm{~dB}$ and omnidirectional radiation pattern. Therefore, the proposed design is a good candidate for modern cognitive radio communications and UWB applications.

\section{Acknowledgments}

The authors gratefully acknowledge UTeM Zamalah Scheme, Universiti Teknikal Malaysia Melaka (UTeM) and the Ministry of Higher Education for supporting this research work.

\section{References}

[1] LIAO, X.-J., YANG, H.-C., HAN, N., LI, Y. UWB antenna with single or dual band-notches for lower WLAN band and upper WLAN band. Electronics Letters, 2010, vol. 46, no. 24 p. 1593-1594. DOI: 10.1049/el.2010.1943

[2] JUSOH, M., JAMLOS, M. F. B., KAMARUDIN, M. R., et al. A reconfigurable ultrawideband (UWB) compact tree-design antenna system. Progress in Electromagnetics Research C, 2012, vol. 30, p. 131-145. DOI: 10.2528/PIERC12041011

[3] OSMAN, M. A. R., ABD RAHIM, M. K., SAMSURI, N. A., et al. Embroidered fully textile wearable antenna for medical monitoring applications. Progress in Electromagnetics Research C, 2011, vol. 117, p. 321-337. DOI: 10.2528/pier11041208

[4] BOUTEJDAR, A., IBRAHIM, A. A., BURTE, E. A compact multiple band-notched planer antenna with enhanced bandwidth using parasitic strip lumped capacitors and DGS-technique. TELKOMNIKA Indonesian Journal of Electrical Engineering. 2015, vol. 13, no. 2, p. 203-208. DOI: 10.11591/telkomnika.v13i2.6976

[5] LABADE, R., DEOSARKAR, S., PISHAROTY, N. Compact integrated Bluetooth UWB antenna with quadruple bandnotched characteristics. International Journal of Electrical and Computer Engineering, 2015, vol. 5, no. 6, p. 1433-1440. ISSN: 2088-8708

[6] BAHADORI, K., RAHMAT-SAMII, Y. A miniaturized ellipticcard UWB antenna with WLAN band rejection for wireless communications. IEEE Transactions on Antennas and Propagation, 2007, vol. 55, no. 11, p. 3326-3332. DOI: 10.1109/TAP.2007.908800

[7] CHU, Q.-X., YANG, Y.-Y. A compact ultrawideband antenna with $3.4 / 5.5 \mathrm{GHz}$ dual band-notched characteristics. IEEE Transactions on Antennas and Propagation, 2008, vol. 56, no. 12, p. 3637-3644. DOI: 10.1109/TAP.2008.2007368

[8] SAM, W. Y., ZAKARIA, Z. A review on reconfigurable integrated filter and antenna. Progress in Electromagnetics Research B, 2015, vol. 63, p. 263-273. DOI: 10.2528/PIERB15082501

[9] HAIDER, N., CARATELli, D., YAROVOY, A. G. Recent developments in reconfigurable and multiband antenna technology. International Journal on Antennas and Propagation, 2013, 14 p. DOI: $10.1155 / 2013 / 869170$

[10] ALHEGAZI, A., ZAKARIA, Z., SHAIRI, N. A., et al. Review of recent developments in filtering-antennas. International Journal on Communications Antennas and Propagation, 2016, vol. 6, no. 3, p. 125-131. DOI: 10.15866/irecap.v6i3.8905

[11] HABIB, M. A., BOSTANI, A., DJAIZ, A., ET AL. Ultra wideband CPW-fed aperture antenna with WLAN band rejection. Progress in Electromagnetics Research, 2010, vol. 106, p. 17-31. DOI: 10.2528/PIER10011905

[12] BARBARINO, S., CONSOLI, F. UWB circular slot antenna provided with an inverted-L notch filter for the $5 \mathrm{GHz}$ WLAN band. Progress in Electromagnetics Research, 2010, vol. 104, p. 1-13. DOI: 10.2528/PIER10040507

[13] SUDHAKAR, A., SATYANARAYANA, M., PRAKASH, M. S., et al. Single band-notched UWB square monopole antenna with 
double U- slot and key shaped slot. In Fifth International Conference on Communication Systems and Network Technologies (CSNT). Gwalior (India), 2015 DOI: 10.1109/CSNT.2015.30

[14] TU, Z., LI, W., CHU, Q. Single-layer differential CPW-fed notchband tapered-slot UWB antenna. IEEE Antennas and Wireless Propagation Letters, 2014, vol. 13, p. 1296-1299. DOI: 10.1109/LAWP.2014.2332355

[15] NOURI, A., DADASHZADEH, G. R. A compact UWB bandnotched printed monopole antenna with defected ground structure. IEEE Antennas and Wireless Propagation Letters, 2011, vol. 10, p. 1178-1181. DOI: 10.1109/LAWP.2011.2171312

[16] XIAO, J. K., ZHU, W. J. New defected microstrip structure bandstop filter. In Progress in Electromagnetics Research Symposium Proceedings. Suzhou (China), 2011, vol. 1, p. 1471-1474.

[17] BOUDAGHI, H., AZARMANESH, M., MEHRANPOUR, M. A frequency reconfigurable monopole antenna using switchable slotted ground structure. IEEE Antennas and Wireless Propagation Letters, 2012, vol. 22, p. 655-658. DOI: 10.1109/LAWP.2012.2204030

[18] LEE, J., KIM, K., RYU, H., WOO, J. A compact ultrawideband MIMO antenna with WLAN band-rejected operation for mobile devices. IEEE Antennas and Wireless Propagation Letters, 2012, vol. 11, p. 990-993. DOI: 10.1109/LAWP.2012.2214431

[19] LUO, G. Q., HONG, W., TANG, H. J., et al. Filtenna consisting of horn antenna and substrate integrated waveguide cavity FSS. IEEE Transactions on Antennas and Propagation, 2007, vol. 55, p. 92-98. DOI: 10.1109/TAP.2006.888459

[20] BARBUTO, M., TROTTA, F., BILOTTI, F., TOSCANO, A. Horn antennas with integrated notch filters. IEEE Transactions on Antennas and Propagation, 2015, vol. 63, no. 2, p. 781-785. DOI: 10.1109/TAP.2014.2378269

[21] BARbuto, M., TrotTA, F., Bilotti, F., TOSCANO, A. Varying the operation bandwidth of metamaterial-inspired filtering modules for horn antennas. Progress in Electromagnetics Research $C, 2015$, vol. 58, p. 61-68. DOI: 10.2528/PIERC15051402

[22] VALIZADE, A., GHOBADI, C., NOURINIA, J., et al. A novel design of reconfigurable slot antenna with switchable band notch and multiresonance functions for UWB applications. IEEE Antennas and Wireless Propagation Letters, 2012, vol. 11, p. 1166-1169. DOI: 10.1109/LAWP.2012.2218271

[23] TASOUJI, N., NOURINIA, J., GHOBADI, C., TOFIGH, F. A novel printed UWB slot antenna with reconfigurable band-notch characteristics. IEEE Antennas and Wireless Propagation Letters, 2013, vol. 12, p. 922-925. DOI: 10.1109/LAWP.2013.2273452

[24] LIN, S. J., WANG, C. C., CHEN, C. C., et al. A high performance IBC-hub transceiver for intrabody communication system. Microwave and Optical Technology Letters, 2012, vol. 54, no. 5, p. 1143-1157. DOI: $10.1002 /$ mop.26797

[25] HU, Z. H., HALL, P. S., KELLY, J. R., et al. UWB pyramidal monopole antenna with wide tunable band-notched behaviour. Electronics Letters, 2010, vol. 46, no. 24, p. 1588-1590. DOI: $10.1049 / \mathrm{el} .2010 .2839$

[26] HORESTANI, A. K., SHATERIAN, Z., NAQUI, J., et al. Reconfigurable and tunable S-shaped split ring resonators and application in band-notched UWB antennas. IEEE Transactions on Antennas and Propagation, 2016, vol. 64, no. 9, p. 3766-3776. DOI: $10.1109 /$ TAP.2016.2585183

[27] SRIFI, M. N., PODILCHAK, S. K., ESSAAIDI, M., et al. Compact disc monopole antennas for current and future ultrawideband (UWB) applications. IEEE Transactions on Antennas and Propagation, 2011, vol. 59, no. 12, p. 4470-4480. DOI: 10.1109/TAP.2011.2165503

[28] ALHEGAZI, A., ZAKARIA, Z., SHAIRI, N. A., et al. Integrated filtering antenna with high selectivity band rejection for UWB applications. Przeglad Elektrotechniczny, 2016, no. 9, p. 224-228. DOI: 10.15199/48.2016.09.55

[29] ABDOLlahVAnd, M., DADASHZADEH, G., MOSTAFA, D. Compact dual band-notched printed monopole antenna for UWB application. IEEE Antennas and Wireless Propagation Letters, 2010, vol. 9, p. 1148-1151. DOI: 10.1109/LAWP.2010.2091250

[30] TAYLOR RAYNO, J., SHARMA, S. K. Frequency reconfigurable spirograph planar monopole antenna (SPMA). In Proceedings of the International Symposium on Antennas and Propagation (ISAP 2012). Nagoya (Japan), 2012, p. 1305-1308.

[31] NXP SEMICONDUCTORS. Silicon PIN diode BAP64-02 (datasheet). 9 p. [Online] Cited 2016-12-20. Available at: http://www.nxp.com/documents/data_sheet/BAP64-02.pdf

[32] SHAIRI, N. A. High Isolation of Single Pole Double Throw Switch with Switchable Resonator for Wireless Communications. PhD thesis. Universiti Teknikal Malaysia Melaka, 2015

[33] RAHMAN, T. A., et al. Reconfigurable Ultra Wideband Antenna Design and Development for Wireless Communication. Project Report. Universiti Teknologi Malaysia, 2008.

[34] TANG, M.-C., ZIOLKOWSKI, R. W., XIAO, S. Compact hyperband printed slot antenna with stable radiation properties. IEEE Transactions on Antennas and Propagation, 2014, vol. 62, no. 6, p. 2962-2969. DOI: 10.1109/TAP.2014.2314299

[35] TANG, M. C., WANG, H., DENG, T.W., ZIOLKOWSKI, R. W. Compact planar ultrawideband antennas with continuously tunable, independent band-notched filters. IEEE Transactions on Antennas and Propagation, 2016, vol. 64, no. 8, p. 3292-3301. DOI: 10.1109/TAP.2016.2570254

[36] DOROSTKAR, M. A., ISLAM, M. T., AZIM, R. Design of a novel super wide band circular-hexagonal fractal antenna. Progress in Electromagnetics Research. 2013, vol. 139, p. 229-247. DOI: 10.2528 /PIER13030505

\section{About the Authors ...}

Ammar ALHEGAZI was born in Sadah, Yemen in 1990. He received his B.Eng. and M.Sc. in Electronic Engineering from the Universiti Teknikal Malaysia Melaka in 2015 and 2017 respectively. He is currently a Ph.D. student at the Faculty of Electronic and Computer Engineering, Universiti Teknikal Malaysia Melaka (UTeM). His research interests include microwave sensors for material characterization and reconfigurable filtering-antennas.

Zahriladha ZAKARIA (Ph.D., MIEEE, BEM, Grad IEM) was born in Malaysia in 1975. He received the B. Eng. and M. Eng. in Electrical and Electronic Engineering from the Universiti Teknologi Malaysia in 1998 and 2004 respectively. He obtained his Doctorate from The University of Leeds in 2010 in the field of Microwave Engineering. From 1998 to 2002, he was with STMicroelectronics, based in Malaysia where he worked as Product Engineer. $\mathrm{He}$ is currently an Associate Professor and the Manager of the Centre for Telecommunication Research and Innovation (CeTRI) at the Faculty of Electronic and Computer Engineering, University Teknikal Malaysia Melaka, where he teaches Electronics, Microwave Engineering and Signal Processing. His research interests include a variety of microwave device developments such as planar and nonplanar microwave filters, amplifiers and antennas. He also 
investigates radio wave propagation as well as energy harvesting for wireless sensor networks and signal processing.

Noor Azwan SHAIRI (PhD, MIEEE) was born in Perak, Malaysia in 1978. He received the Bachelor in Engineering (Electrical-Telecommunication) and the Master in Electrical Engineering (By Research) from Universiti Teknologi Malaysia (UTM), in 2002 and 2005, respectively. In 2015, he obtained his Doctorate from Universiti Teknikal Malaysia Melaka (UTeM) in the field of Electronic Engineering (RF and Microwave). His early employment was at the Wireless Communication Centre, UTM developing automated antenna measurement system, programming of Bluetooth proximity for communication system and RF transceiver design for WLAN application. In 2005, he was in Flextronics Technology (Malaysia), working as an RF Engineer on Failure Analysis (FA) for various RF/Microwave products. From 2006 to 2008, he worked as a R\&D Engineer at Avago Technologies (Malaysia) developing automated RF/Microwave test system and designing RF attenuators and RF switches. From October 2008 until now, he is a Lecturer at the Faculty of Electronics and Computer Engineering (FKEKK), Universiti Teknikal Malaysia Melaka (UTeM), Malaysia. His research areas are mainly focused on RF and microwave engineering such as transmitter and receiver design (for WLAN/WiMAX/ LTE), RF/microwave active and passive circuit design (such as switches, filters \& resonators); test and measurement of RF/microwave devices.

Azahari SALLEH graduated from Universiti Teknologi Malaysia, Malaysia with Bachelor of Electrical Engineering (Telecommunication) in 2003 and Master of Electrical Engineering (Electronics \& Telecommunications) in 2008. $\mathrm{He}$ is the Head of the Dept. of Telecommunication Engineering in the Faculty of Electronics and Computer Engineering, Universiti Teknikal Malaysia Melaka (UTeM). Currently he works as a lecturer in the same university. He is a member of Board of Engineering Malaysia (B.E.M) and the Institute of Electrical and Electronics Engineers (IEEE).

Sharif AHMED was born in Razah, Sadah,Yemen on 7th September 1991. He received his Bachelor's degree in Wireless Communication Engineering from the Universiti Teknikal Malaysia Melaka (UTeM) in 2014.He is currently working toward the master degree in rectifying antennas (rectennas) designs. His research interests are antennas and rectifiers designs for RF energy harvesting applications. 